\title{
NOTES AND CORRESPONDENCE Effect of Land on Aerosols in Oceanic Atmosphere under the Westerly Monsoon
}

\author{
By Hiroshi Kojima and Toshio Sekikawa \\ Faculty of Science and Technology, Science University of Tokyo, \\ Faculty of Science, Science University of Tokyo \\ (Manuscript received 23 March 1977, in revised form 20 November 1977)
}

\section{Introduction}

For the study of the air pollution of global scale, measurements of aerosols in the oceanic atmosphere are very important and were already carried out by several authors (Cobb et al. 1970, Junge et al. 1971, Misaki et al. 1972, Kojima et al. 1974, Elliot 1976).

Hogan et al. (1973) made a map of aerosols through the measurements in different parts of oceanic atmosphere.

Some authors (Sagalin et al. 1956, Misaki et al. 1970, Morita et al. 1973) measured aerosols in the oceanic atmosphere from the origin on land to mid-ocean and tried to find out the general tendency of the change of particle size as well as particle concentration along the route of their travel from land to ocean.

In order to investigate the transport behavior of aerosol from land to ocean more effectively, we took the following procedures.

(1) As the observing place, we selected two islands (Miyake and Hachijyo) in the Pacific Ocean (Fig. 4); Miyake is of about $170 \mathrm{~km}$ and Hachijyo of about $290 \mathrm{~km}$ off-shore southward from Tokyo.

(2) As the time of observation, we selected the days in February 1974; in this month the westerly monsoon prevails in this region of the Pacific Ocean.

From Fig. 4, we see easily that the air masses, fully contaminated by aerosols during the time of passage over the Japan proper, will arrive at these islands under the westerly monsoon. Therefore we may expect to find some important clues to clarify the transport behavior by analyzing our data.

\section{Observation}

The observations were made on the total particle concentration using Pollack counters during the period 2 to 17 February 1974.
Since we should have the data which are completely free from the contamination arising from the islands, we payed adequate attention to the location of the setting of the measuring apparatus. At Miyake, they were set at the northern fringe of the island and the sample air was introduced at $10 \mathrm{~m}$ above the sea surface; at Hachijyo, they were set at the north-western fringe and at about $50 \mathrm{~m}$ apart from sea shore.

With these arrangements we may say safely, as long as westerly monsoon is blowing, that the air at the both locations will not be influenced by the contaminations of local origins.

Data at the two islands were obtained every five minutes using two Pollack counters of the same type. The Pollack counters we used had been carefully calibrated in our laboratory. At Miyake, we also used an absolute counter (Kojima et al. 1973) regularly (three times a day) to calibrate our Pollack counter further.

\section{Results and data analysis}

In Fig. 1, we show two typical examples of hourly variation of aerosol concentration: one for the day of westerly monsoon (Feb. 11, 1974) and the other for the day of other wind direction (Feb. 4, 1974).

We see clearly in this figure the following two facts.

(1) On the day of westerly monsoon, aerosol concentration shows pronounced diurnal variation with a maximum. On the day of other wind direction, however, it does not show such regular pattern of diurnal variation. But as our data might be influenced by local contaminations on the day of other wind direction, we can not draw any conclusions from the apparent change of these data.

(2) The patterns of diurnal variation on the day of westerly monsoon are nearly the same except in their phases. From our data (Fig. 
1), the increase of aerosol concentration begins at about $10 \mathrm{~h}$ and a maximum appears at about $18 \mathrm{~h}$ or $19 \mathrm{~h}$ at Miyake; at Hachijyo the increase at about noon and a maximum at about $20 \mathrm{~h}$ or $21 \mathrm{~h}$.

In Fig. 2 we show the patterns of the average diurnal variation of 6 days observations under westerly monsoon for each island. From this figure, we can show that the phase difference in the diurnal variations between Hachijyo and Miyake is about two hours.

In order to obtain the most probable value of the above time-lag between Hachijyo and Miyake, we calculated a cross correlation; the correlation coefficient $\gamma_{M H}$ between $N_{H}$ at Hachijyo and $N_{M}$ at Miyake is calculated from the following formula using hourly data of 24 hours.

$$
r_{M H}(L)=\frac{\Sigma N_{M}^{\prime}(t) \cdot N_{H}^{\prime}(t+L)}{\sqrt{\Sigma N^{\prime} M^{2}(t) \cdot \sqrt{\Sigma N^{\prime}{ }_{H}^{2}(t)}}}
$$

where (') denotes deviation from the mean value, and $L$ denotes the adopted time-lag in the calculation. The result is shown in Fig. 3. From this, we conclude that the time-lag or the phase difference in the diurnal variations is 2 or 3 hours.

This time-lag can be explained by the transport of air masses. Air mass trajectories for $850 \mathrm{mb}$ level have frequently been used for transport of aerosols (e.g. Reiquam 1970). Accordingly we calculated air mass trajectories of 12 hours length which passed through Hachijyo at $9 \mathrm{~h}$ and $21 \mathrm{~h}$ J.S.T. of days restricted to westerly monsoon,
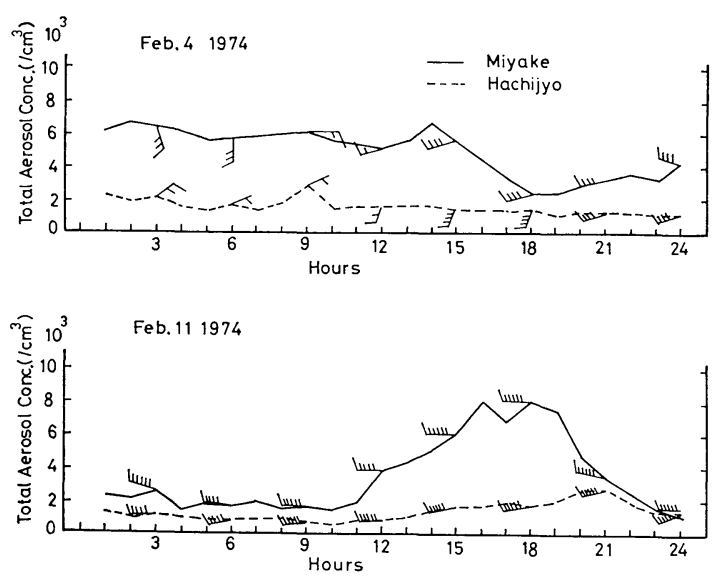

Fig. 1 Time variation of total aerosol concentration under westerly monsoon (on $11 \mathrm{Feb}$.) and other wind direction (on 4 Feb.). The wind direction and velocity are indicated by Beaufort wind scale for each point in the figure. using upper air charts of $850 \mathrm{mb}$ level (Fig. 4). From these trajectories the amount of time spent over ocean prior to Hachijyo was interpolated.

As there were no data on upper wind at Miyake, we can not obtain such trajectories with the same method described above. So, it was assumed that the direction and length of air mass trajectories for Miyake were equal to those for Hachijyo. We believe that this assumption does not lead to much errors of the air mass trajectories because the distance between the two islands is short compared with the scale of pressure pattern on air charts.

In this way, we obtain the following average values for the elapse time since air mass has left on land.
$4.8 \pm 0.3$ hours
$2.1 \pm 0.2$ hours
for Hachijyo, for Miyake.

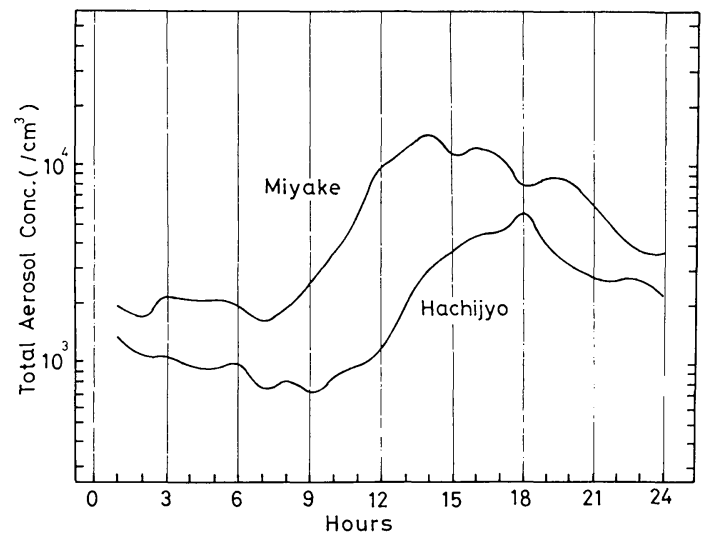

Fig. 2 Average diurnal variation of aerosols under westerly monsoon.

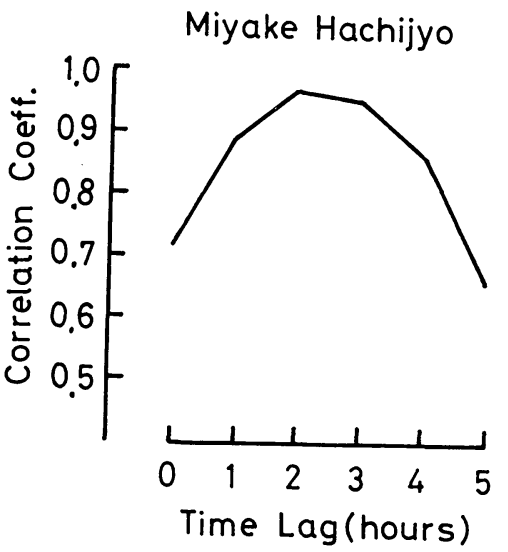

Fig. 3 The relation between the correlation coefficient and the time-lag. 


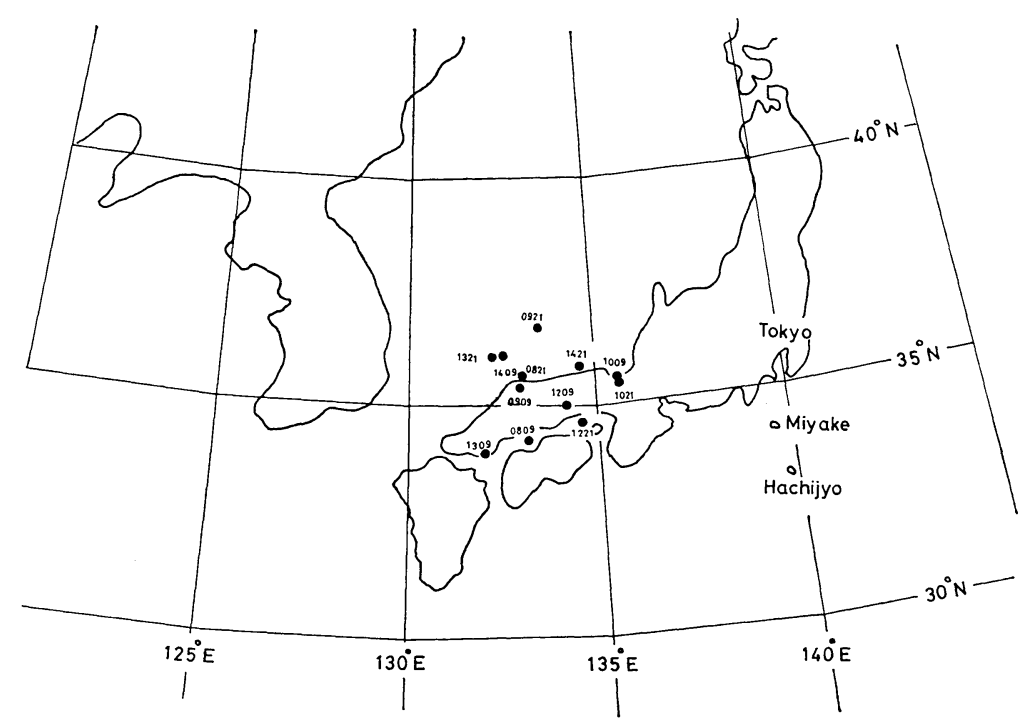

Fig. 4 The original points on the trajectories of 12 hours length which passed through Hachijyo. Data are abbreviated in the fourdigit number. The first two digits give the day and the second two the hour.

We see that the time difference of about 2.7 and can be considered as a kind of long line hours between both islands is nearly equal to the source of aerosols under westerly monsoon, (2) time-lag between diurnal variations shown in Fig. the distances of both islands from Japan proper 3. If we assume that the phase of diurnal vari- are short compared with the length of this line ation on land is the same at every part of Japan source and (3) the air masses which passed proper, this coincidence of two time differences indicates that the tendency of diurnal variation of aerosols on land are transported to the distance of about $200 \mathrm{~km}$ in oceanic atmosphere under westerly monsoon.

\section{Conclusion}

From the observation on two small islands (one about $170 \mathrm{~km}$ and the other about $290 \mathrm{~km}$ from Tokyo) in the Pacific Ocean, we obtained the following two results.

(1) Aerosol concentrations on two islands show pronounced diurnal variation with a maximum, on days of westerly monsoon.

(2) The time-lag between diurnal variations of two islands was 2 or 3 hours.

These two results can be explained by the transport of contaminated air over Japan proper at $850 \mathrm{mb}$ level.

There are few papers which report the existence of such a diurnal variation of the aerosol concentration in the oceanic atmosphere. The reasons why we found pronounced diurnal variation are as follows: (1) Japan proper is a long island through the two islands under westerly monsoon are those which had been contaminated by aerosols over Japan proper several hours before.

\section{Acknowledgements}

We express our sincere thanks to Professor $\mathrm{H}$. Ishikawa and his staffs of Nagoya University for their helpful advices in making the plan of this study. Also we are indebted to research students of Sekikawa laboratory for their technical assistance in the aerosol measurements.

\section{References}

Cobb, W. E. and H.J. Wells, 1970: The electrical conductivity of oceanic air and its correlation to global atmospheric pollution. J. Atmos. Sci., 27 , 814-819.

Elliott, W.P., 1976: Condensation nuclei concentrations over the Mediterranean sea. Atmos. Environ., 10, 1091-1094.

Hogan, A. W., V. A. Mohnen and V. J. Schafer, 1973: Comments on oceanic aerosol levels deduced from measurements of the electrical conductivity of the atmosphere. J. Atmos. Sci., 30, 14551460. 
Junge, A. and R. Jaenicke, 1971: New results in background aerosols studies from the Atlantic expedition of the R. V. Meteor., spring 1969. J. Aerosol Sci., 2, 305-314.

Kojima, H. and T. Sekikawa, 1973: The problems on the measurements of condensation nuclei. Tenki, 20, 300-306.

$$
\text { , and 1974: Some characteristics }
$$

of background aerosols over the Pacific Ocean. J. Meteor. Soc. Japan, 52, 499-505.

Misaki, M. and T. Takeuti, 1970: The extension of air pollution from land over ocean as revealed in the variation of atmospheric electrical conductivity. J. Meteor. Soc. Japan, 48, 263-269.

M. Ikegami and I. Kanazawa, 1972:

Atmospheric electrical conductivity measurement in the Pacific Ocean exploring the background level of global pollution. J. Meteor. Soc. Japan, 50, 497-500.

Morita, Y., H. Ishikawa, J. Nagasawa and M. Kanada, 1973: The land to ocean transitional behavior of the atmospheric electric parameters and their relation to atmospheric pollution. J. Meteor. Soc. Japan, 51, 294-306.

Reiquam, H., 1970: Sulfur simulated long range transport in the atmosphere. Science, 170, 318320.

Sagalyn, R. C. and G. A. Faucher, 1956: Space and time variation of charged nuclei and electrical conductivity of the atmosphere. Quart. J. Met. Soc., 82, 428-445.

\title{
冬の季節風下での, 海洋大気上エアロゾルへの陸地の影響
}

\author{
児島 紘・関川俊男
}

東京理科大学・理工学部・理学部 